\title{
NoTES AND ANNOUNCEMENTS
}

\section{ErRatum}

Drug Utilization Review of Cholinesterase Inhibitors in Quebec Can. J. Neurol. Sci. 2008; 35: 508-9

Fadi Massoud, Marc Dorais, Claudie Charbonneau,

Bénédicte Lescrauwaet, Jean-Marc Boucher,

Jacques LeLorier

Please note this work was supported by Pfizer Canada. Pfizer was not involved in the data analyses performed. Claudie Charboneau and Benedicte Lescrauwaet who were employees of Pfizer Canada contributed to the interpretation of the data, reviewed and commented this manuscript.

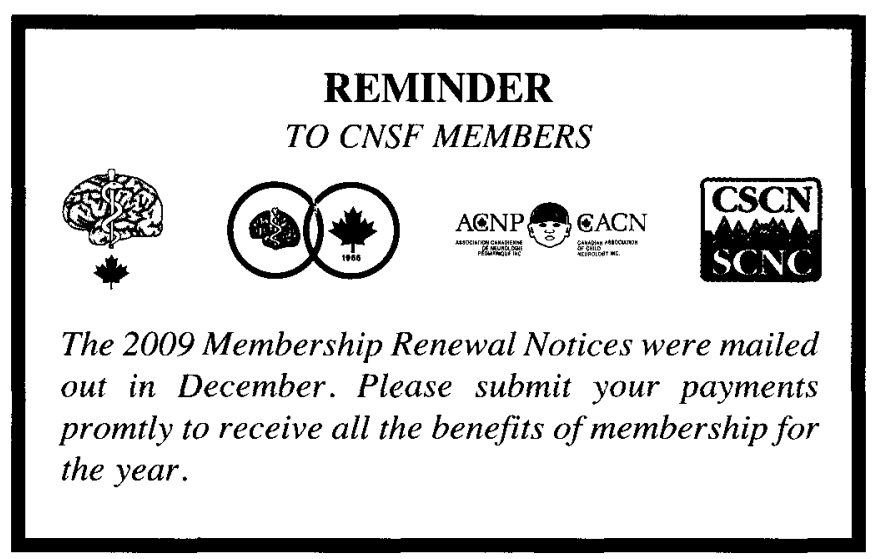

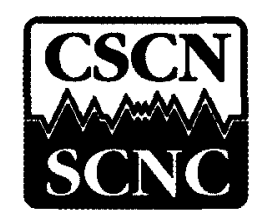

\section{EMG AND EEG EXAMINATIONS}

To assure and maintain a high standard of competence in clinical electroencephalography and electromyography across Canada, the Canadian Society of Clinical Neurophysiologists $(\mathrm{CSCN})$ conducts an annual examination in EEG and EMG and related subjects for those eligible physicians entering EEG or EMG practice who elect to take it. Successful candidates will be given a certificate by the $\mathrm{CSCN}$ and will automatically be eligible for Active membership in the Society.

The Provincial Licensing Bodies and the Royal College of Physicians and Surgeons of Canada have been informed of this examination and of the objective of the CSCN to maintain high standards in the practice of Clinical Neurophysiology in Canada.
For eligibility, location and fees, please go to the CNSF website

http://www.cnsfederation.org/cscn_index.html

\section{MAKE A DIFFERENCE TO YOUR PROFESSION AND BECOME A JOURNAL REVIEWER}

The Canadian Journal of Neurological Sciences is always looking for talented and skilled reviewers to submit timely and high quality reviews of manuscripts. Without these volunteers, the Journal cannot maintain a steady stream of high quality, informational articles relevant to readers.

Reviewing for the Journal supports Canadian clinical neurosciences. Make it your top refereeing priority.

The Benefits of Becoming a Reviewer:

- An annual record of all your refereeing contributions for academic promotional purposes.

- Your name included in the "Thank you to Reviewers" list in the March issue of the Journal.

- Eligibility for the "Distinguished Reviewer of the Year" award, recognizing extensive, timely and high quality reviews.

- Reviewers who regularly contribute to the Journal are considered for the Editorial Board.

- Credits towards your Maintenance of Certification.

- Serving as a Journal reviewer supports your Journal and Canadian clinical neurosciences.

Contact the Canadian Journal of Neurological Sciences

E-mail: journal@cjns.org 